\title{
Quantitative and Qualitative Assessment of Using PBL in a Mechanical Measurements Class
}

\author{
Sudhir Mehta \\ North Dakota State University
}

\begin{abstract}
McKeachie and Gibbs, in their tenth edition of Teaching Tips, say, "Problem-based Learning (PBL) is one of the most important developments in contemporary higher education." This paper gives a brief introduction to PBL and describes a PBL module that was developed, implemented, and assessed in a Mechanical Measurements class. The assessment results indicate that the PBL method significantly improves important skills such as analyzing and solving open ended, real-world problems; finding, evaluating, and using appropriate learning resources; working cooperatively in teams; and communicating effectively, verbally and in writing. Our study, like many other studies, also indicates that there was no gain in students' performance on standard tests and exams, and more research is needed. However, it is important to note that students' performance on the standard tests and exams did not decline either. Based on the above results, we are planning to increase the number of PBL exercises in the measurements course with the support from the NSF and industry.
\end{abstract}

\section{Introduction}

The Boyer Commission's report from the Carnegie Foundation, "Reinventing Undergraduate Education: A Blueprint for American's Research Universities” (Boyer, 1998), provides an academic bill of rights for students. It includes (1) Providing opportunities to learn through inquiry rather than simple transmission of knowledge, (2) Training in the skills necessary for oral and written communication, and (3) Preparing students carefully and comprehensively for whatever may lie beyond graduation.

Several other reports (NRC, 1996, 2000; NSF, 1996; Kuwana, 1997) indicate that there is a need for change in undergraduate education. The educators calling for change bemoan the lack of relevancy in many traditional courses and recommend eliminating the "plug-and-chug" cookbook approach to education. In a traditional or content-based approach, the emphasis is on covering as much material as possible, and that emphasis often creates difficulty for instructors. The huge quantity of material also makes it impossible for students to develop deeper understanding of the subject matter.

A driving force behind this change is the realization that successful employment and citizenship at the present time requires different knowledge and skills than in the past (NRC, 1996, 1999). Hence, in addition to instructors' more traditional role as providers of discipline-specific knowledge, they are being urged to adopt teaching strategies that help students to develop competencies identified as necessary for success:

- To analyze and solve open-ended, real-world problems, 
- To find, evaluate, and use appropriate learning resources,

- To work cooperatively in teams, and

- To communicate effectively, verbally and in writing.

Many of the reports mentioned earlier suggest several strategies to develop these skills. One of the most common strategies recommended is to use the problem-based learning (PBL) method of instruction.

\section{Problem-Based Learning (PBL)}

PBL had its beginning in the medical program at McMaster University in Hamilton, Ontario, Canada. Later, it was implemented in the medical programs at Michigan State and Harvard Universities. Currently, most medical schools are using the PBL method of instruction, and its use has proliferated in some other disciplines (Wilkerson and Gijselaers, 1996). A limited number of engineering educators have reported using PBL methods in their classes (Smith et al., 1997; Woods, 1997; Brown and Brown, 1997; Havener and Dull, 1998). However, no PBL work is reported for a measurements course.

The typical characteristics or features of PBL are described in Table 1. A comparison of a PBL method and the traditional approaches is given in Figure 1.

\section{Table 1. Typical Features of the PBL Method}

1. Problems are designed to emulate real-world problems.

2. Problems used are complex and cover multiple objectives.

3. The problem or task is introduced FIRST, before any learning occurs.

4. Learning procedures, facts, and concepts occurs within the context of finding a solution to the problem.

5. Specific procedures or algorithms are learned as needed.

6. Additional structure for learning is proportional to the experience level of the learner.

7. Much of the structure for learning is provided through in-depth questioning by the instructor.

8. Students using this process usually work in cooperative or collaborative groups to gain multiple perspectives on possible solutions.
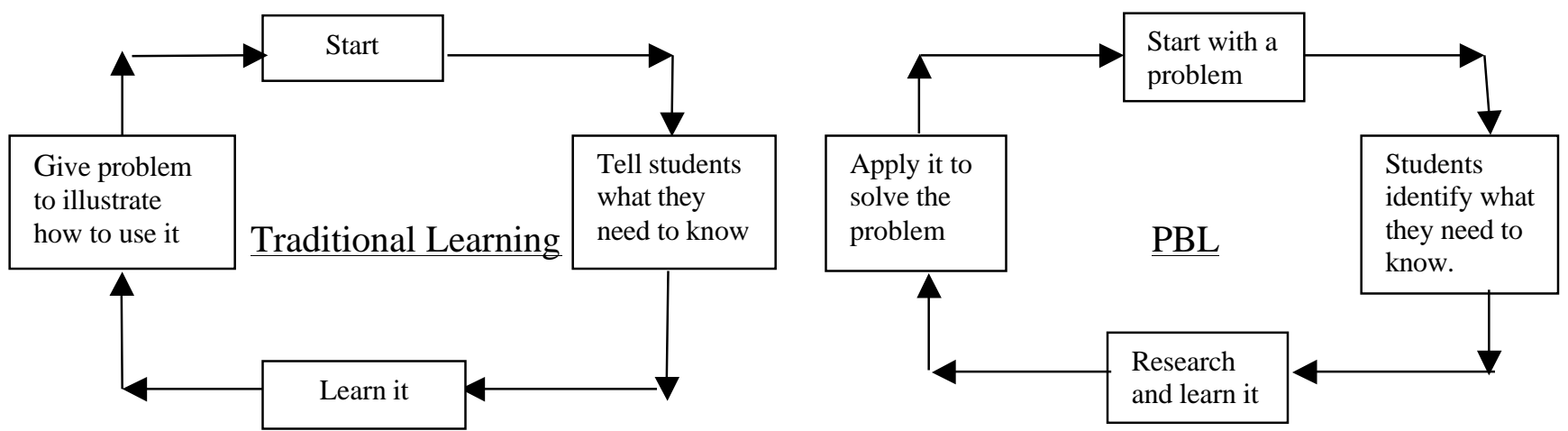

Figure 1. Traditional and Problem-Based Learning Processes

"Proceedings of the 2002 American Society for Engineering Education Annual Conference \& Exposition Copyright $($ C 2002, American Society for Engineering Education" 
A teacher's role in a PBL mode of instruction changes quite significantly from that in a traditional mode of instruction. The teacher must act as a coach and facilitator for students as they go about finding the solution to a problem. Expected outcomes of using PBL are listed in Table 2. Brief descriptions of PBL and its expected outcomes provide a glimpse of why many educational leaders consider PBL as one of the most effective pedagogies that will address a national need of enhancing undergraduate education.

\section{Table 2. Expected Outcomes When Using PBL}

1. Since learning occurs in an environment similar to that in which the students will work, the problem-solving skills they learn will be more easily transferable to that work environment.

2. Students no longer learn facts, skills, and concepts as separate entities, but instead see how they can be interconnected to solve real problems.

3. Students learn to find, evaluate, and use appropriate learning resources.

4. Students enhance their skill to work in teams.

5. Students increase their communication skills by explaining the results of their independent research to team members and presenting a final report.

\section{Method and Assessment Data}

Engineering Measurements is a required course in the Mechanical Engineering (ME) curriculum at North Dakota State University, like in many ME curriculums at other universities. It consists of two 50-minute recitations and one two-hour laboratory. Typically, the course contains error analysis, different types of sensors, signal conditioning, and computerized data acquisition systems.

A PBL module for the temperature measurement unit was introduced using a real-world problem of instrumenting some parts of a power plant (please see Appendix). In this exercise, students, working in small groups, identified what they needed to know (learning issues) to solve this problem. The instructor's role during this exercise was that of a facilitator, pointing students in the right direction mainly by asking questions (as in the Socratic style). Students researched their part of the learning issues independently and updated their team members. Finally, each team came to consensus and recommended two (the best and an alternative) solutions. Each team gave a written report and an oral presentation. The instructor completed the discussion by highlighting important items either missed by students or not addressed by the current problem. This exercise took two weeks to complete.

The PBL project on temperature measurement was done after the first test and before the second test. The students mainly learned the temperature measurement component on their own by doing the PBL project while the other components of the course were taught using the traditional teaching method. The traditional tests had numerical problems and multiple-choice concept questions. The PBL project was evaluated based on a group report (30\%), group presentation (10\%), individual research work (30\%), individual critical evaluation of PBL (15\%), and peer evaluation (15\%). The quantitative data from the two tests and the PBL project are given in Table 3. 
Table 3. Data from the Two Tests and PBL Project $(\mathrm{N}=43)$

\begin{tabular}{|l|r|r|r|r|}
\hline ITEMS & $\begin{array}{r}\text { Average } \\
\text { Score }\end{array}$ & $\begin{array}{r}\text { Max. } \\
\text { Possible } \\
\text { Score }\end{array}$ & Std. Dev. & $\begin{array}{r}\text { Average } \\
\text { Score in } \\
\text { Percentage }\end{array}$ \\
\hline Test - 1 Numerical Problems (Non-PBL) & 13.4 & 20 & 4.2 & 67 \\
\hline Test - 1 Concept Questions (Non-PBL) & 7.1 & 10 & 1.5 & 71 \\
\hline Test - 1 Total (Non- PBL) & 20.4 & 30 & 5.1 & 68 \\
\hline Test - 2 Numerical Problems (Non-PBL) & 11.0 & 14 & 2.7 & 79 \\
\hline Test - 2 Numerical Problem (PBL) & 5.1 & 6 & 1.4 & 86 \\
\hline Test - 2 Concept Question (Non-PBL) & 3.1 & 5 & 0.9 & 63 \\
\hline Test - 2 Concept Questions (PBL) & 3.5 & 5 & 1.1 & 69 \\
\hline Test - 2 Total & 22.8 & 30 & 4.1 & 76 \\
\hline PBL Project & 27.0 & 30 & 1.1 & 90 \\
\hline
\end{tabular}

These assessment data indicate that student performance on the PBL parts of the regular tests did not decrease, even though students themselves learned most of the material. Actually, the performance was marginally higher (statistically not significant). However, the performance on the PBL project was significantly higher than the test performance. The results indicate that we must evaluate PBL courses in multiple ways. This concept is in line with the comments made in the Kuwana (1997) report, "PBL also sparks concerns about how faculty are to assign individual grades. Those who are concerned about scoring student achievement might look to industry for guidance. On the job, people's competency and contributions are evaluated in any number of ways, including portfolios, peer reviews, self-assessments, and final product."

The students in the class were individually asked to examine advantages and drawbacks of the PBL method compared to the traditional method of instruction. Some of the most frequently occurring student comments are given in Table 4.

Table 4. Student Comments on Advantages and Drawbacks of the PBL Method

\begin{tabular}{|c|}
\hline Advantages \\
\hline 1. More practical and hands-on approach. \\
\hline 2. Better retention of what you research and explain to others. \\
\hline 3. Learn to work better in a group. \\
\hline 4. Much higher level of interest and engagement. \\
\hline 5. Solving real-life problems prepare us better for our jobs \\
\hline Drawbacks \\
\hline 1. Takes more time. \\
\hline 2. Relying on other group members for your own learning is not very effective. \\
\hline 3. Scheduling is difficult. \\
\hline 4. Materials covered or learned appear less. \\
\hline 5. The instructor is teaching less and making us learn on our own. \\
\hline
\end{tabular}

At the end of the semester, students were asked to compare some of the items related to enhancing their skills in a PBL class with other similar, non-PBL classes. The rating scale used was very good (5), good (4), neutral (3), poor (2), and very poor (1). The results of the feedback

"Proceedings of the 2002 American Society for Engineering Education Annual Conference \& Exposition Copyright (C) 2002, American Society for Engineering Education" 
are given in Table 5. They indicate that PBL appears to have an advant age over the traditional method for enhancing the desired skills.

Table 5. Student Perception of Skills Developed in a PBL and Non-PBL Class $(\mathrm{N}=42)$

\begin{tabular}{|l|c|c|c|c|}
\hline \multirow{2}{*}{ Skills } & \multicolumn{2}{c|}{ In a PBL Class } & \multicolumn{2}{c|}{ In a Non-PBL Class } \\
\cline { 2 - 5 } & Average & Std. Dev. & Average & Std. Dev. \\
\hline $\begin{array}{l}\text { Ability to obtain information } \\
\text { from a variety of sources }\end{array}$ & 4.0 & 0.76 & 3.2 & 0.81 \\
\hline $\begin{array}{l}\text { Ability to work in a team, like } \\
\text { on a real job }\end{array}$ & 4.1 & 0.88 & 3.3 & 0.95 \\
\hline $\begin{array}{l}\text { Ability to solve real-life, open- } \\
\text { ended problem }\end{array}$ & 4.1 & 0.77 & 3.2 & 0.69 \\
\hline
\end{tabular}

Note: Average values of PBL and Non-PBL classes were statistically different at $\alpha=0.001$.

The instructor's observations and analysis also form a part of the overall assessment, and are provided in this paragraph. Making the transition from a traditional lecture-type class format to a PBL format is fairly complex for both faculty and students. On the challenges side, not all students (or colleagues) like this change; the process is time consuming; and there are very few "good" problems and assessment tools. On the positive side, the PBL process seems to be one of the best methods to enhance "real" learning skills, and it is recommended by leading educators and industry representatives. We conclude our observations by quoting Barbara Duch, Director of the Science and Education Resource Center at the University of Delaware, "Would I return to a traditional lecture format? Not a chance. The excitement and energy of a room of students working in groups, teaching each other, challenging each other, and questioning each other is what I'll always want to see in my classroom" (Kuwana, 1997).

\section{Conclusions}

Wilbert McKeachie and Graham Gibbs, in their tenth edition of Teaching Tips (1999), say, "Problem-based Learning is one of the most important developments in contemporary higher education." PBL is used in most medical schools, and it has the potential of having a profound effect on undergraduate education. Patricia Cross, in her American Society for Engineering Education (ASEE) 1991 Annual Convention keynote address, said, "Teaching is in a primitive state of development, and improvement can take place all along the line. The real intellectual challenge of teaching lies in the opportunity for individual teachers to observe the impact of their teaching on students' learning. And yet, most of us don't use our classroom as laboratories for the study of learning." As educators, we should take up the challenge of experimenting with PBL and assess its impact on student learning.

The main purpose of academic assessment is to review the present situation and make necessary changes for improving the education process (Angelo and Cross, 1993; Mehta and Schlecht, 1998). This assessment study indicates that the PBL method significantly improves important skills such as analyzing and solving open-ended, real-world problems; finding, evaluating, and using appropriate learning resources; working cooperatively in teams; and communicating effectively, verbally and in writing. Our study, like many other studies, also indicates that there was no gain in students' performance on standard tests and exams. However, it is important to 
note that students' performance on the standard tests and exams did not decline either. Based on the above results and the support from the National Science Foundation, we are planning to increase the number of PBL exercises in the measurements course and develop educational materials for other instructors. Representatives from Rosemount Incorporation, MTS Corporation, Medtronics, and Phoenix International Company are supportive of the PBL method and have agreed to provide real-life problems. The PBL materials for the measurements course will be tested at four other universities. We believe that other educators should also consider testing the PBL method of instruction in different engineering subjects, and the assessment approach used in this paper can easily be applied to study its impact on enhancing student learning in their course(s).

\section{Acknowledgements}

This work is partially supported by the National Science Foundation (NSF) Grant No. DUE0126671. The proposal, "Developing and Assessing Impact of Problem-Based Learning Materials " is funded by the Division of the Undergraduate Education (DUE) at the NSF under their Course, Curriculum, and Laboratory Improvement (CCLI) Program and the Educational Materials Development (EMD) Track.

\section{References}

1. Angelo, T. \& Cross, P. (1993). Classroom Assessment Techniques: A Handbook for College Teachers. Jossey Bass Publisher, San Francisco, CA.

2. Boyer (1998). "Reinventing Undergraduate Education: A Blueprint For America's Research Universities," A report from the Carnegie Foundation, http://notes.cc.sunysb.edu/Pres/boyer.nsf. [March 30, 2001].

3. Brown, B. Sr. and Brown, B. Jr. (1997). "Problem-Based Education (PROBE): Learning for a lifetime of Change," Proceedings, ASEE National Conference, Milwaukee, WI, http://www.asee.org/conferences/search/.

4. Cross, P. (1991). “On College Teaching,” Journal of Engineering Education, Vol. 82, 1, pp. 9-15.

5. Havener, A. and Dull, C. (1998). "An Information Resource Web-Page for a Freshman Problem Based Learning Engineering Course," Proceedings, ASEE National Conference, Seattle, WA, http://www.asee.org/conferences/search/.

6. Kuwana, T. (1997). "Curricular Developments in the Analytical Sciences," A report from the NSF Workshops, Chemistry department, University of Kansas, Lawrence, KS.

7. McKeachie, W., and Gibbs, G. (1999). Teaching Tips: Strategies, Research, and Theory for College and University Teachers, $10^{\text {th }}$ ed., Houghton Mifflin, Boston, MA.

8. Mehta, S \& Nem, S. (1998). "Computerized Assessment Technique for Large Classes," Journal of Engineering Education, Vol. 87, 2, pp. 167-172.

9. NSF. (1996). "Shaping the Future: New Expectations for Undergraduate Education in Science Mathematics, Engineering, and Technology," Report \# NSF 96-139, http://www.ehr.nsf.gov/ehr/due/documents/review/96139/start.htm. [March 30, 2001]. 
10. NSF. (1993). "User Friendly Handbook for Project Evaluation: Science, Mathematics, Engineering and Technology Education," http://www.ehr.nsf.gov/EHR/RED/EVAL/Handbook/handbook.htm. [March 30, 2001].

11. NRC. (2000). How people learn: Brain, Mind, Experience, and School (expanded edition). National Research Council's Commission on Behavioral and Social Sciences and Education: Developments in the Science of Learning and Learning Research and Educational Practice. National Academy Press, Washington, DC. Full text can be found at http://books.nap.edu/catalog/9853.html. [March 30, 2001].

12. NRC. (1999). "Transforming Undergraduate Education in Science, Mathematics, Engineering, and Technology," A report from NRC, http://books.nap.edu/catalog/6453.html. [March 30, 2001].

13. NRC. (1996). "From Analysis to Action: Undergraduate Education in Science, Mathematics, Engineering, and Technology," A report from NRC, http://books.nap.edu/catalog/9128.html. [March 30, 2001].

14. Smith K., et al. (1997). "Problem-Based Freshman Engineering Course," Proceedings, ASEE National Conference, Milwaukee, WI, http://www.asee.org/conferences/search/.

15. Wilkerson, L. and Gijselaers, W. (1996). "Bringing Problem-based Learning to Higher Education: Theory and Practice," Editors, New Directions for Teaching and Learning, 68, Jossey-Bass, San Francisco, CA.

16. Woods, D. et al. (1997). "Developing Problem Solving Skills: The McMaster Problem Solving Program," Journal of Engineering Education, pp. 75-92.

\section{Biography}

Sudhir Mehta is a professor of Mechanical Engineering at North Dakota State University. His areas of interest are enhancing student learning, measurements, controls, robotics, mechanics, design optimization, and machine vision. He was named the 1997 North Dakota Professor of the Year by the Carnegie Foundation and has received the HP award for excellence in laboratory instruction in 1999. He was awarded university's prestigious Faculty Lectureship Award in 2001 and the Peltier Award for Innovative Teaching in 2000. Dr. Mehta and his colleagues have received the best paper awards from the ASEE in 1999 and 1995. He is a co-author of the courseware, "Statics: The Next Generation," which is electronically published by Prentice-Hall in August 2001. He has co-authored two CDROM's containing hypermedia based instrumentation and communication resource modules. He has also developed innovative techniques for active learning, collaborative learning, and quick assessment. He and his colleagues have received several grants from the NSF, 3M, and HP to enhance engineering education. Dr. Mehta received the Carnot Award for the best teacher of the year, four times, from the students of Pi Tau Sigma Society. His e-mail address is sudhir.mehta@ndsu.nodak.edu. 


\title{
Appendix. A Typical PBL Project and Assessment Tools
}

\author{
From the desk of Chief Engineer \\ Basin Electric Power Cooperative, Bismarck, ND
}

February 29, 20xx

Dear Members of Instrumentation Engineering Team,

As you are aware that the construction for unit 2 at the Leland Olds Station in Stanton, ND began in July 1971 at a cost of $\$ 109$ million. It has a capacity of $440 \mathrm{MW}$. This second unit began commercial operation in December 1975. This unit is going through complete remodeling and I would like your team to suggest instruments for measuring water/steam temperatures at the inlet and outlet of the boiler, turbine, and condenser.

I would like you to give your final selections, the rational for selecting them and cost of the units. In the appendix, please include other alternatives considered and their advantages and disadvantages.

I will appreciate it, if your group can present the results at the board meeting to be held in the week of March 20 during your lab period.

If you have any questions, please let me know.

Sincerely,

Sudhir Mehta

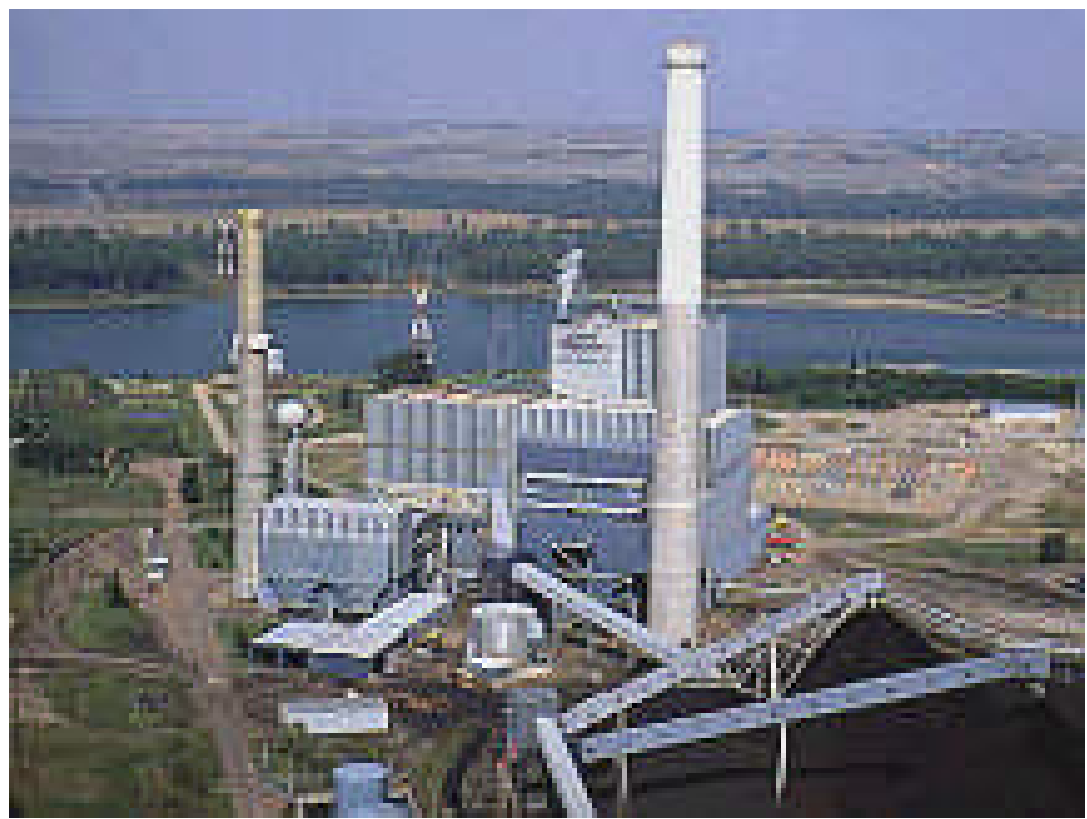

Leland Olds Station

"Proceedings of the 2002 American Society for Engineering Education Annual Conference \& Exposition Copyright (C) 2002, American Society for Engineering Education" 


\section{ME 412 Temperature Project Using PBL}

Learning Issues:

1. Specifications of Process Parameters:

What are the parameters (ranges of $\mathrm{T}$ and $\mathrm{P}$ ) at the input and output of the boiler, turbine, and condenser? How did you determine them?

2. Types of sensors (their theory, characteristics, applications, etc.):

Thermocouple

RTD / Thermistor

Their principles of operation (from temperature to the desired electrical output)

Their types, range, accuracy, precision, response time, etc.

\section{Commercial information}

Cost of the complete sensor assembly

Initial cost, maintenance, etc.

\section{A Picture of Engineering Measurements Class Working on a PBL Project}

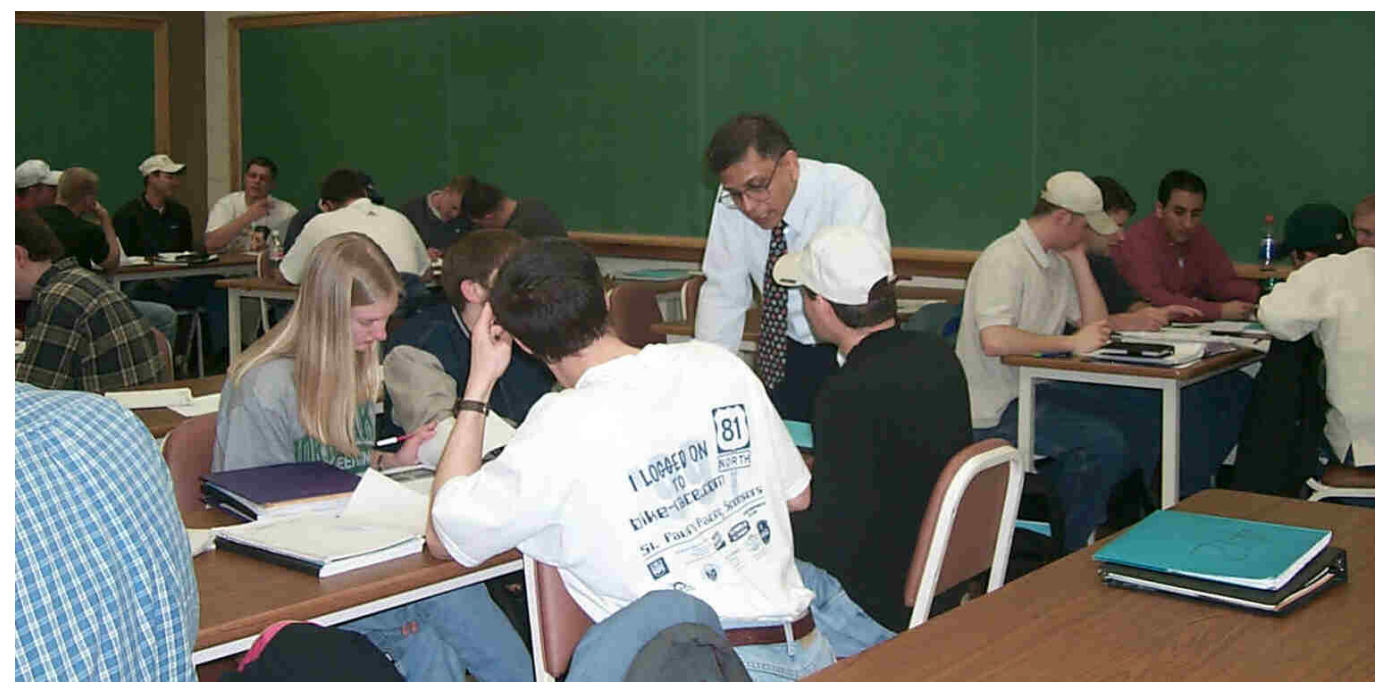

ME 412 Evaluation: Temperature Project Report

Name:

Section:

1. Group Report (30\%) :

2. Group Presentation (10\%):

3. Individual Contribution / Activity Log (30\%):

4. Peer and Self Evaluation for individual effort (15\%):

5. A critical evaluation of a PBL mode of instruction (15\%):

TOTAL: 
Peer and Self Assessment Form (Allen, 2000)

Your Name

Names of Group Members: $\quad 1$.

2.

3.

4.

Please use the following form to assess the contributions of everyone in your group, including yourself. Using the following scale, rate each member of your group $(1,2,3$, and 4). Then rate yourself under the column "you" using the following scale:

5 = strongly agree $\longrightarrow 1=$ strongly disagree.

$\begin{array}{lllllll} & 1 & 2 & 3 & 4 & \text { You }\end{array}$

1. Completed assigned work thoroughly.

2. Completed assigned work on time.

3. Contributed relevant information when solving group problem.

4. Asked questions in a way that promoted clearer understanding of problem.

5. Answered group members' questions in a way that promoted understanding.

6. Fulfilled his/her role of responsibility.

7. Overall, I rate this individual's contribution to our group effort: 5: excellent $\longrightarrow$ 1: very poor

Additional comments on individuals:

1.

2.

3.

4. 